\title{
RE-EXAMINATION OF FAULT MODEL FOR THE 1982 URAKAWA-OKI EARTHQUAKE BY ANALYSES OF SEISMIC, GEODETIC, AND TSUNAMI DATA
}

\author{
Daisuke SUETSUGU* and Ichiro NAKANISHI \\ Department of Geophysics, Faculty of Science, \\ Hokkaido University, Sapporo, Japan
}

(Received June 22, 1987)

\begin{abstract}
A fault model of the 1982 Urakawa-Oki earthquake is determined by analyzing seismic, geodetic, and tsunami data. Using Rayleigh waves with periods longer than $200 \mathrm{~s}$ and $\mathrm{P}$-wave first motions we obtain the source mechanism characterized by a reverse fault with the P-axis of the NE-SW direction. The seismic moment is $2.7 \times 10^{26} \mathrm{dyn} \cdot \mathrm{cm}$. The fault model is constrained but not uniquely determined by aftershock distribution and leveling data. Tsunami simulation for actual ocean bottom topography helps us infer the fault parameters. Comparison of tide gauge records and the simulated tsunamis shows that the fault model inclined from the Pacific Ocean to the inland of Hokkaido provides the best fit to the observation. The fault model has a dimension of $12 \times 22 \mathrm{~km}^{2}$ on a plane dipping $39^{\circ}$ toward $\mathrm{N} 30^{\circ} \mathrm{E}$. The average dislocation is estimated to be $2.5 \mathrm{~m}$. The generation of the earthquake may be ascribed to the collision of the Kuril arc with the Tohoku arc.
\end{abstract}

\section{Introduction}

On March 21, 1982, the Urakawa-Oki earthquake $(M=7.1)$ occurred offshore Urakawa, Hokkaido (Fig. 1). The epicenter, focal depth, and origin time of this event were determined by MORIYA et al. (1983): Epicenter, $42.172^{\circ} \mathrm{N}, 142.578^{\circ} \mathrm{E}$; Focal depth, $25.8 \mathrm{~km}$; Origin time (UT), $2 \mathrm{~h} 32 \mathrm{~min} 5.7 \mathrm{~s}$. This is one of the largest events in this region and studies on fault models of the event may reveal tectonics of Hokkaido of the present time.

The focal process of this earthquake has been investigated by TADA (1982, 1987) and TAKEO et al. (1983). Although all of the previous studies have used the same data-set based on seismic and geodetic observations, they have drawn different conclusions on the fault model: TAKEO et al. (1983) and TADA (1982) have proposed fault models inclined toward the southwest, while TADA (1987) has obtained a model inclined toward the northeast.

* Present address: Department of Geophysics, Faculty of Science, the University of Tokyo, Tokyo, Japan. 


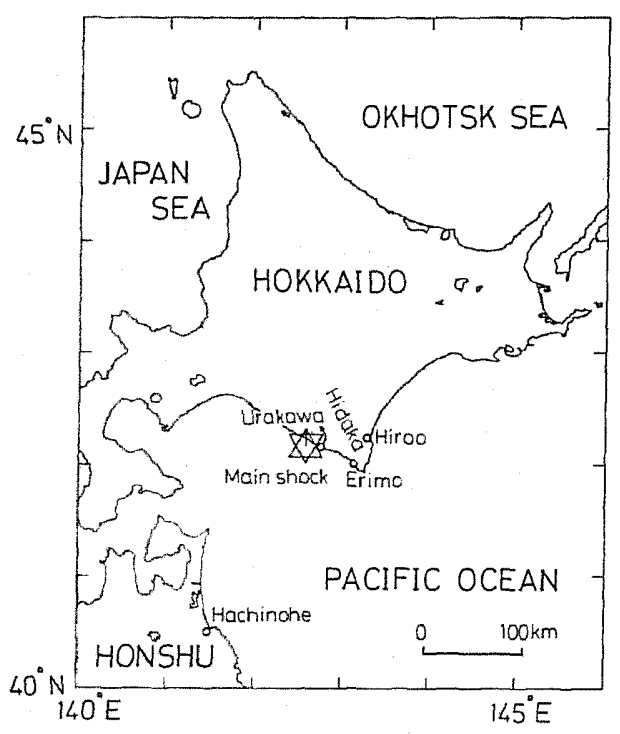

Fig. 1. The source region of the 1982 Urakawa-Oki earthquake. Star represents the epicenter and open circles the tide gauge stations used in this study.

In the present study we infer the fault parameters by using tsunami data as well as the data used in the previous studies. Since the tsunami waveforms have information on vertical displacements of the sea-floor directly above the hypocenter, the tsunami analysis may provide strong constraints on the fault parameters.

\section{Method}

Analyses are made through the following steps: (1) determination of the source mechanism and the seismic moment by a waveform inversion of seismic waves; (2) analysis of crustal deformation to obtain fault models which explain leveling data along a shore-line near the focal area; (3) tsunami analysis to derive the final solution to the fault model.

\subsection{Determination of source mechanism and seismic moment}

We determine the seismic moment tensor by the waveform inversion. The vertical components of seismograms $V$ are related to the moment tensor $\boldsymbol{M}$ by

$$
A M=V,
$$

where $\boldsymbol{A}$ is a matrix representing the excitation of the spheroidal oscillations calculated by using the normal mode theory (TAKEUCHI and SAITO, 1972) with the earth model PREM (DZIEWONSKI and ANDERSON, 1981). Both $\boldsymbol{A}$ and $\boldsymbol{V}$ are bandpassed by a Chebyshev filter with a pass-band of 200-600 s. The trace of the 
moment tensor is assumed to be zero in this study. Equation (1) is stably solved for deep events. For shallow events such as the Urakawa-Oki earthquake, however, it is difficult to determine the full elements of the moment tensor (KANAMORI and GIVEN, 1981).

We use P-wave first-motion data as well as waveform data to determine the moment tensor. The far-field $\mathrm{P}$-wave displacement $r(i, \theta)$ is written by

$$
r(i, \theta)=\boldsymbol{B}(i, \theta) \boldsymbol{M},
$$

where $i$ denotes a take-off angle at a source, $\theta$ azimuth of a receiver measured clockwise from the north, $\boldsymbol{B}$ an excitation matrix of P-wave (e.g., STrelrTZ, 1978; FITCH et al., 1980). The additional constraints for the moment tensor are expressed by

$$
\boldsymbol{B}_{k} \boldsymbol{M} \geq 0 \text { (for compression at the } k \text {-th receiver) }
$$

or

$$
\boldsymbol{B}_{k} \boldsymbol{M} \leq 0 \text { (for dilatation at the } k \text {-th receiver) }
$$

We solve Eq. (1) for $M$ under the constraints (3) by a linear least squares method with linear inequality constraints (LAWSON and HANSON, 1974). TANIMOTO and KANAMORI (1986) have applied a linear programming method to determine a moment tensor in the frequency domain under the $\mathrm{P}$-wave first-motion constraints. It is easier to implement our approach in routine analyses to obtain the moment tensor solution than TANIMOTO and KANAMORI's (1986) approach, since our method does not require an initial guess for the solution while TANIMOTO and KANAMORI's (1986) method does.

Following KANAMORI and Given (1981) we obtain the best double couple and the seismic moment $M_{0}$ from the moment tensor.

\subsection{Analysis of crustal deformation}

The angles of dip, strike, and slip of the fault models are taken from the two nodal planes obtained by the moment tensor solution. The remaining parameters of the faults (location of the center of fault, the fault length $L$, the width $W$, the dislocation $D$ ) are determined by comparing the crustal deformation observed along a shore-line near the focal area and the deformation calculated from the fault models. The aftershock distribution is taken into consideration in this procedure.

Some parts of the observed crustal deformation may be attributed to the largest aftershock $(M=5.9)$, which took place eight hours after the main shock, because its depth is shallow $(9.5 \mathrm{~km}$ ) and the epicenter is located in the coastal region (MORIYA et al., 1983). We must estimate the contribution of the largest aftershock to the observed crustal deformation in order to obtain the fault model for the main shock.

Since we have no observation to infer the fault parameters $L, W, D$ of the largest aftershock, we tentatively use an empirical relation among the fault parameters of shallow earthquakes (ABE, 1975; GELLER, 1976): 


$$
W / L=0.5
$$

and

$$
D / L=2 \times 10^{-5} \text {, }
$$

where $D, W$, and $L$ are given in units of $\mathrm{km}$, and the relation between the seismic moment $M_{0}$ and the fault parameters:

$$
M_{0}=\mu D W L,
$$

where $\mu$ denotes the rigidity. Combining Eq. (4) with Eq. (5), we have

$$
L=\left(M_{0} / \mu \times 10^{5}\right)^{1 / 3} \text {. }
$$

The calculation of the crustal deformation is made with the semi-infinite homogeneous medium by relying on the formulation of MANSINHA and SMYLIE (1971).

\subsection{Tsunami analysis}

We follow AIDA (1978) to carry out the tsunami simulation using seismic fault models. The basic equations are the shallow-water long-wave equations

$$
\frac{\partial Q_{x}}{\partial t}=-g(d+H) \cdot \frac{\partial H}{\partial x}
$$

and

$$
\frac{\partial Q_{y}}{\partial t}=-g(d+H) \cdot \frac{\partial H}{\partial y},
$$

and the continuity equation

$$
\frac{\partial}{\partial t}(H-\eta)=-\frac{\partial Q_{x}}{\partial x}-\frac{\partial Q_{y}}{\partial y}
$$

where $Q_{x}$ and $Q_{y}$ are the flow rates in $x$ and $y$ directions, $g$ the gravitational acceleration, $d$ the water depth, $H$ the surface elevation of water, and $\eta$ the vertical displacement of the sea bottom. We take the $x$ direction to be parallel to the axis of the Kuril trench and the $y$ direction perpendicular to it. Equations (7) and (8) are solved by a finite-difference method with a square grid system. The standard grid size is $5 \times 5 \mathrm{~km}^{2}$. The finer grid sizes $(2.5,1.25$, and $0.625 \mathrm{~km})$ are used for the regions where tide gauges are installed. The grid sizes become smaller toward the tide gauge station. The grid sizes and the time step of computation $(10 \mathrm{~s})$ satisfy the stability condition of the finite-difference scheme. The initial flow rates are set to zero. The initial water levels are assumed to be equal to the vertical displacements of the sea bottom which are calculated by the MANSINHA and SMYLIE's (1971) method from the fault models obtained by the analysis of crustal deformation data. The temporal change of water levels at tide gauge stations is computed and compared 
with the observations for the first cycles of the waves since the later parts are strongly affected by smaller-scale coastal topography than we model.

\section{Results}

\subsection{Source mechanism and seismic moment}

Rayleigh waves recorded at IDA (International Deployment of Accelerograms) (AGNEw et al., 1976) network and GDSN (Global Digital Seismic Network) are used in the waveform inversion for the Urakawa-Oki earthquake and its largest aftershock, respectively. The IDA and GDSN stations used in this study are shown in Fig. 2. As additional constraints to the source mechanism we use P-wave firstmotions read from the long-period WWSSN (Worldwide Standard Seismograph Network) seismograms and those reported by JMA (Japan Meteorological Agency), RCEP (Research Center for Earthquake Prediction, Hokkaido University), and ISC (International Seismological Centre).

As illustrated in Fig. 3 the source mechanisms of the main shock and the largest aftershock are characterized by the reverse faults with the P-axes of the NE-SW direction. In Table 1 we present the angles of strike $\phi$, dip $\delta$, and slip $\lambda$ which are defined by using the convention of AKI and RICHARDS (1980, p 106). The observed

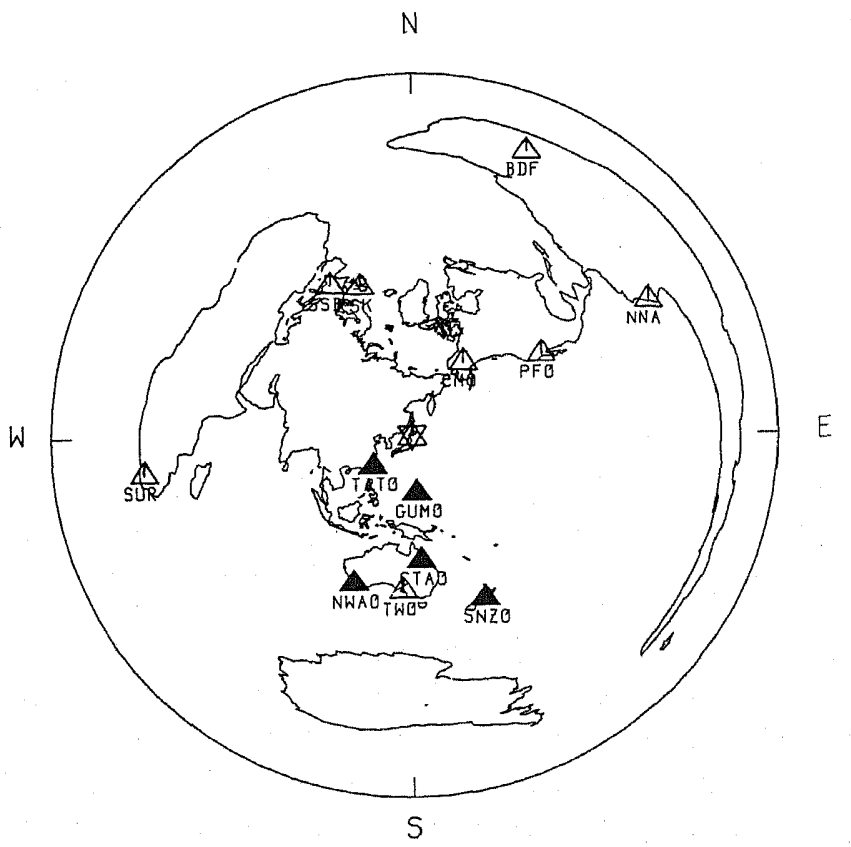

Fig. 2. Azimuthal equi-distant projection centered on the epicenter of the Urakawa-Oki earthquake. The IDA (open triangles) and the GDSN (solid triangles) stations used in this study are shown. 

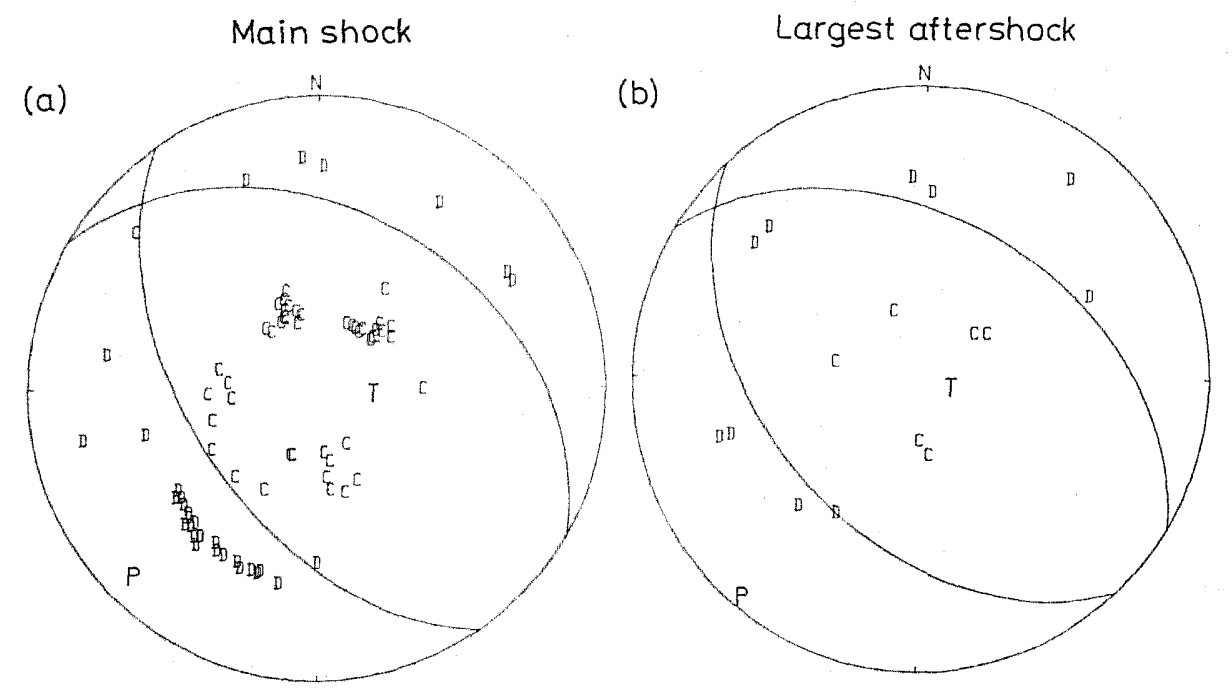

Fig. 3. Source mechanisms of the best double couple determined by the waveform inversion. $\mathrm{C}$ represents the compression and $\mathrm{D}$ the dilatation. $\mathrm{P}$ and $\mathrm{T}$ indicate pressure and tension axes. Equal area projection of the lower hemisphere is shown. (a) Main shock. (b) Largest aftershock.

Table 1. Source parameters of the best double couples.

\begin{tabular}{|c|c|c|c|c|}
\hline & \multicolumn{2}{|c|}{ Urakawa-Oki earthquake } & \multicolumn{2}{|c|}{ Largest aftershock } \\
\hline & Nodal plane 1 & Nodal plane 2 & Nodal plane 1 & Nodal plane 2 \\
\hline$\phi()$ & 300 & 146 & 300 & 136 \\
\hline$\delta\left({ }^{\prime}\right)$ & 39 & 54 & 45 & 46 \\
\hline$\lambda(1)$ & 70 & 106 & 78 & 101 \\
\hline$M_{\mathrm{o}}(\mathrm{dyn} \cdot \mathrm{cm})$ & \multicolumn{2}{|c|}{$2.7 \times 10^{26}$} & \multicolumn{2}{|c|}{$2.3 \times 10^{24}$} \\
\hline
\end{tabular}

seismograms and synthetics calculated from the obtained moment tensor are shown for the main shock in Fig. 4. The nodal plane solutions and the seismic moments are consistent with those obtained by TAKEO et al. (1983) and DZIEWONSKI et al. (1983).

\subsection{Analysis of crustal deformation}

Leveling surveys along the shore-line around the epicentral area were repeated ten months before and a month after the occurrence of the Urakawa-Oki event (GEOGRAPHICAL SURVEY INSTITUTE, 1982). The elevation change during this period (about a year) is considered to be due to the Urakawa-Oki earthquake and the largest aftershock.

Figure 5 shows hypocenters of the aftershocks located by a joint inversion for the hypocenters and the three-dimensional velocity structure (MrYAMACHI and 

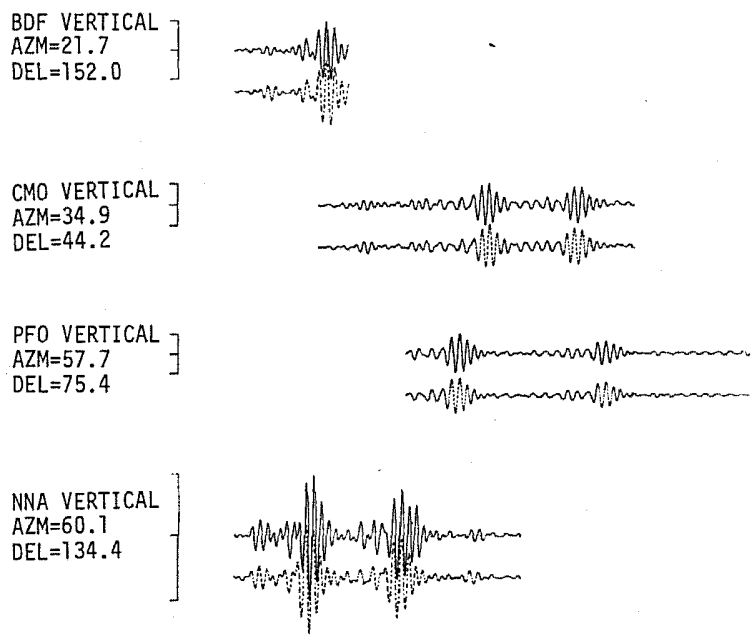

TWO VERTICAL
AZM=183.4
$D E L=77.7$

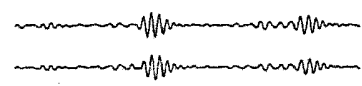

SUR VERTICAL
$A Z M=262.7$
$D E L=133.5$

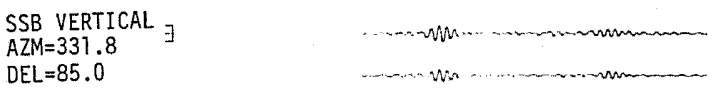

$\mathrm{DEL}=85.0$

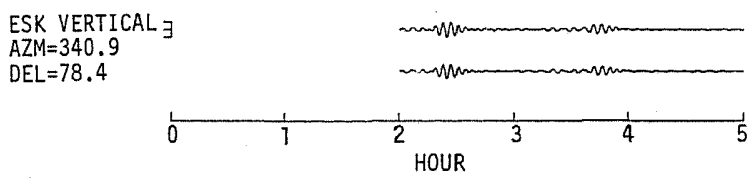

Fig. 4. Comparison of the observed seismograms (solid lines) with the synthetics (broken lines) for the main shock. The distance and azimuth of each station are shown on the left of each trace.

MORIYA, 1987). Three groups of aftershocks have been suggested by MIYAMACHI and MorIYA (1987) and are shown in Fig. 5. The groups seem to be located on planes, while scatters around the planes are rather large. The dip and strike of group 1 are close to those of the nodal plane 1 of the main shock, and groups 2 and 3 close to the nodal plane 2. We make three trial fault models 1,2 , and 3 of the main shock, which correspond to the aftershock groups 1,2 , and 3 , respectively. The dip and strike of model 1 are assumed to be identical to the values of the nodal plane 1 of the main shock and those of models 2 and 3 the nodal plane 2. We test which model can 

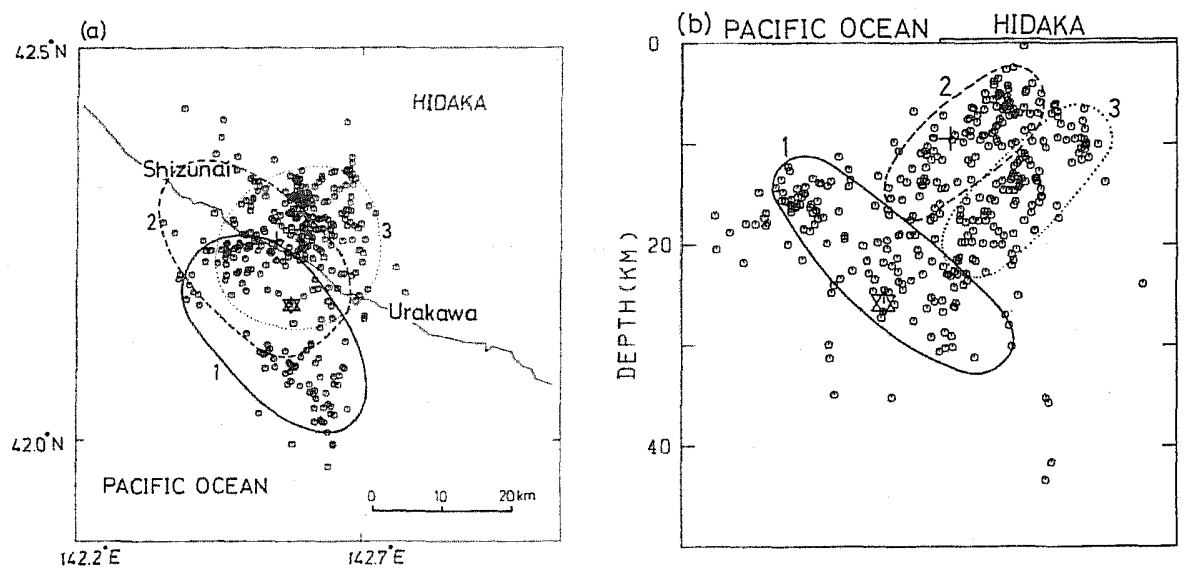

Fig. 5. Aftershock distribution obtained by MiYAMACHI and MORIYA (1987) during the period from 24 March to 24 June, 1982. Stars denote the main shock, crosses the largest aftershock. Areas surrounded by solid, broken, and dotted curves denote the groups 1,2, and 3, respectively. (a) Epicenters. (b) Hypocenters projected onto a vertical plane striking $\mathrm{N} 30^{\circ} \mathrm{E}-\mathrm{S} 30^{\circ} \mathrm{W}$ direction. The vertical and horizontal scales are identical.

explain the observed crustal deformation and tsunami waveform.

The largest aftershock belongs to group 2 (Fig. 5). We recognize the nodal plane dipping toward the southwest as the fault plane of the largest aftershock, since the strike and dip of the nodal plane are close to those of the group 2. Assuming the rigidity $\mu=3 \times 10^{11} \mathrm{dyn} / \mathrm{cm}^{2}$ we obtain the fault parameters of the largest aftershock presented in Table 2 . The fault model of the largest aftershock produces vertical displacements as small as $2 \mathrm{~cm}$. We allow for the contribution of the largest aftershock to the crustal deformation in the present analysis. Alternative choice of the fault plane of the largest aftershock does not change fundamental conclusions on the fault model of the main shock because the crustal deformation calculated from the two fault models of the largest aftershock are both small.

The fault parameters of the main shock are determined for each group by a trial-and-error procedure, so that the fault models for the main shock and the largest aftershock should provide an adequate fit to the observed vertical displacements. The parameters of the fault models for the main shock are presented in Table 2. Figures 6-8 show that the fault models for all the groups produce similar displacements along the shore-line and can explain the leveling data. It is noted that the displacement fields on the sea-floor offshore Urakawa calculated from the fault models are different, by a factor of three, from each other. The difference of displacements on the sea-floor may lead to the difference of tsunami heights and their waveforms. 

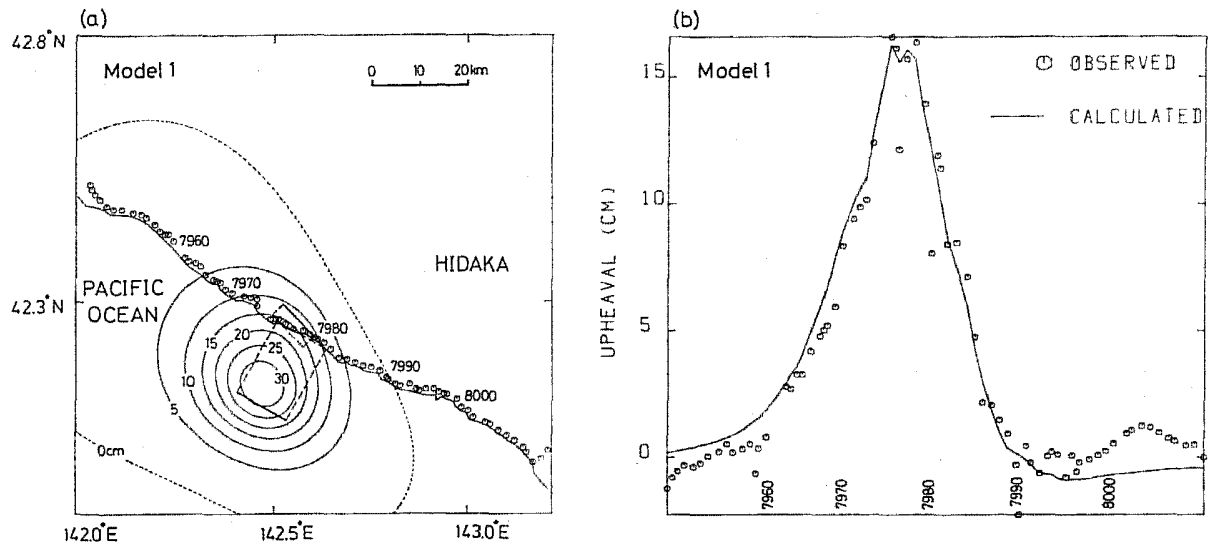

Fig. 6. (a) Crustal deformation computed from the fault model 1 and the fault model of the largest aftershock. Contour lines represent vertical displacements. The large and the small rectangles are the fault models for the main shock and the largest aftershock, respectively. Solid lines of the rectangles denote the upper rims of the faults. Locations of bench marks (open circles) are shown. (b) Comparison of the observed displacements (open circles) with the displacements calculated from the model I and the fault model of the largest aftershock (solid line) along the leveling route.
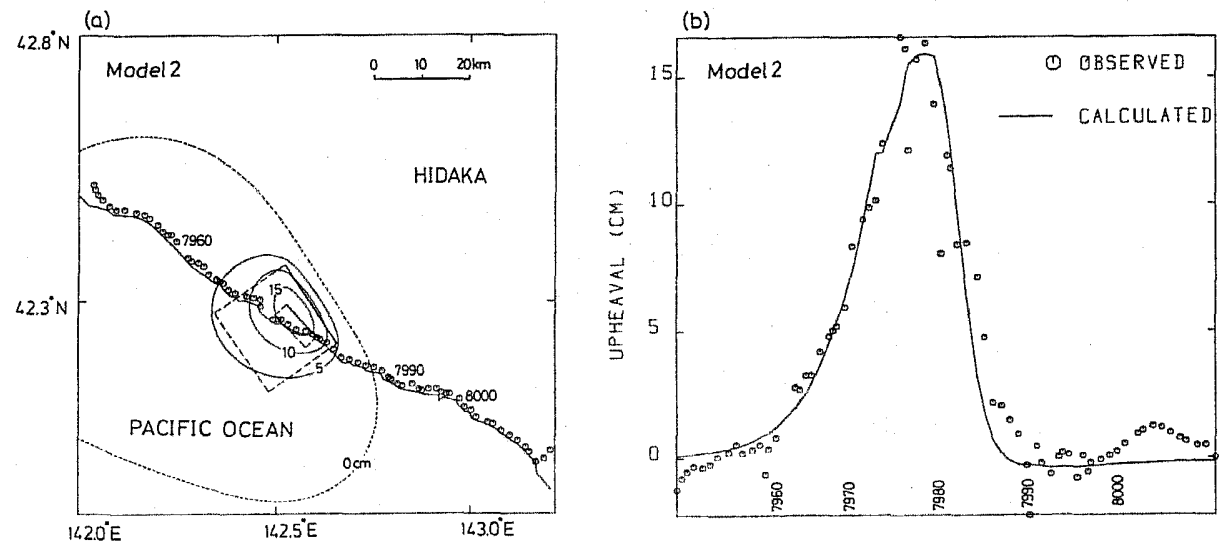

Fig. 7. Same as Fig. 6 but for the fault model 2.

\subsection{Tsunami analysis}

HATORI (1982) and TAKAHASHI and YAKUWA (1983) have reported that tsunamis caused by the Urakawa-Oki earthquake were observed from Miyako in the Tohoku region to Nemuro in Eastern Hokkaido. Tide gauge records at Urakawa, Erimo, Hiroo, and Hachinohe (Fig. 1 for location) are used in the course of the present analysis, since these records have high $\mathrm{S} / \mathrm{N}$ ratios. 

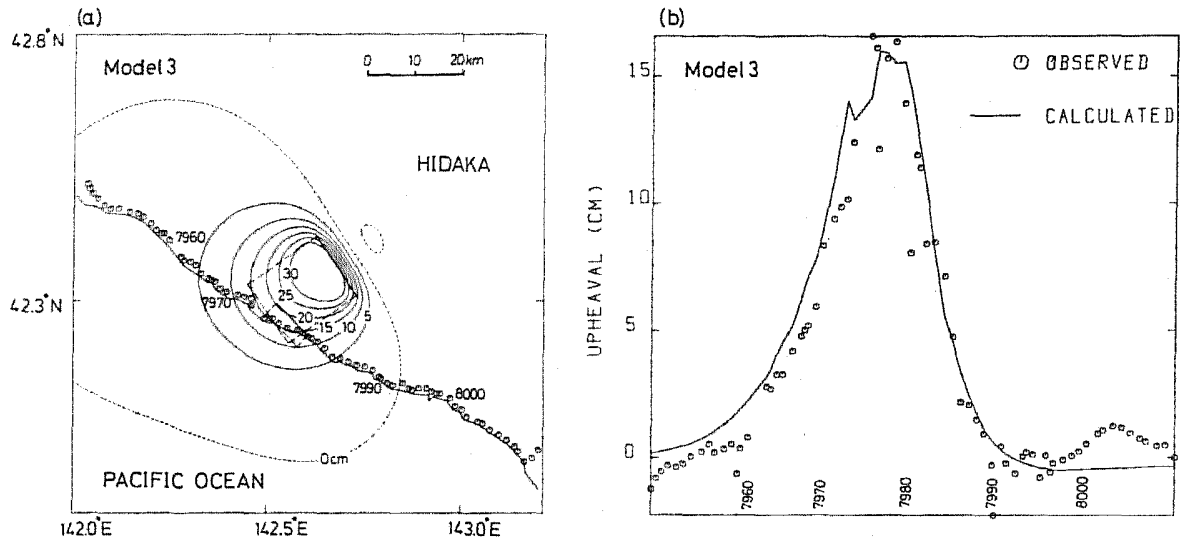

Fig. 8. Same as Fig. 6 but for the fault model 3.

Table 2. Fault parameters.

\begin{tabular}{lrrrrrrr}
\hline & $L(\mathrm{~km})$ & $W(\mathrm{~km})$ & $D(\mathrm{~m})$ & $h(\mathrm{~km})$ & $\phi\left({ }^{\circ}\right)$ & $\delta\left(^{\circ}\right)$ & $\lambda\left({ }^{\circ}\right)$ \\
\hline Model 1 & 12 & 22 & 2.5 & 14 & 300 & 39 & 70 \\
Model 2 & 20 & 30 & 0.4 & 5 & 146 & 54 & 106 \\
Model 3 & 15 & 30 & 1.2 & 5 & 146 & 54 & 106 \\
Largest aftershock & 9 & 5 & 0.2 & 8 & 136 & 46 & 101 \\
\hline
\end{tabular}

$h$ denotes depth of the upper rim of a fault.

Figures 9-11 show comparisons of the observed tsunami waveforms and the synthetics computed for Erimo and Urakawa from the fault models given in Table 2. The fault model 1 shows the best fit to the observations among the three fault models. The wave heights resulting from the other models are much lower than the observations. We adopt model 1 as the final fault model for the Urakawa-Oki earthquake in the present study.

The tsunami heights predicted from all the fault models are considerably lower than the observations at Hachinohe and Hiroo. Figure 12 shows the tsunami waves calculated from model 1 for Hachinohe and Hiroo. ABE (1983) has shown that the maximum peak to peak amplitude observed at Hachinohe was larger than those at other stations, taking into account propagation distances of the tsunamis. AIDA (1969) has reported that the tsunami of the 1968 Tokachi-Oki earthquake observed at Hachinohe had amplitudes much larger than those expected from fault models based on seismic data. The small-scale topography which is not taken into consideration in our simulations may cause the anomalous wave heights.

\section{Discussion and Conclusion}

We have constructed the simple fault model which explains the long-period 


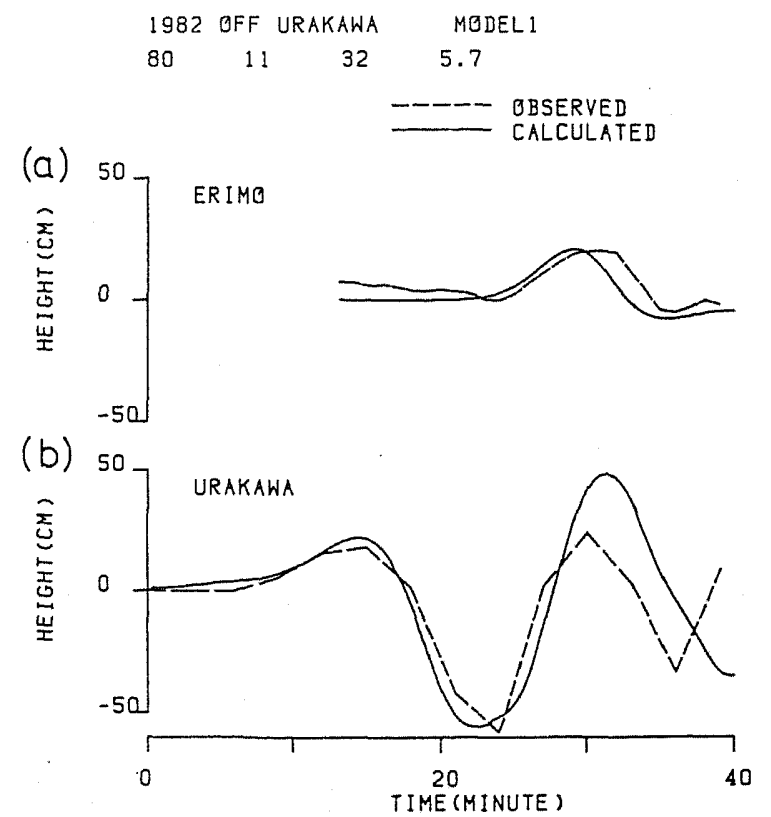

Fig. 9. Comparison of the observed (broken lines) and simulated (solid lines) tsunami waveforms for the fault model 1. (a) Erimo. (b) Urakawa.

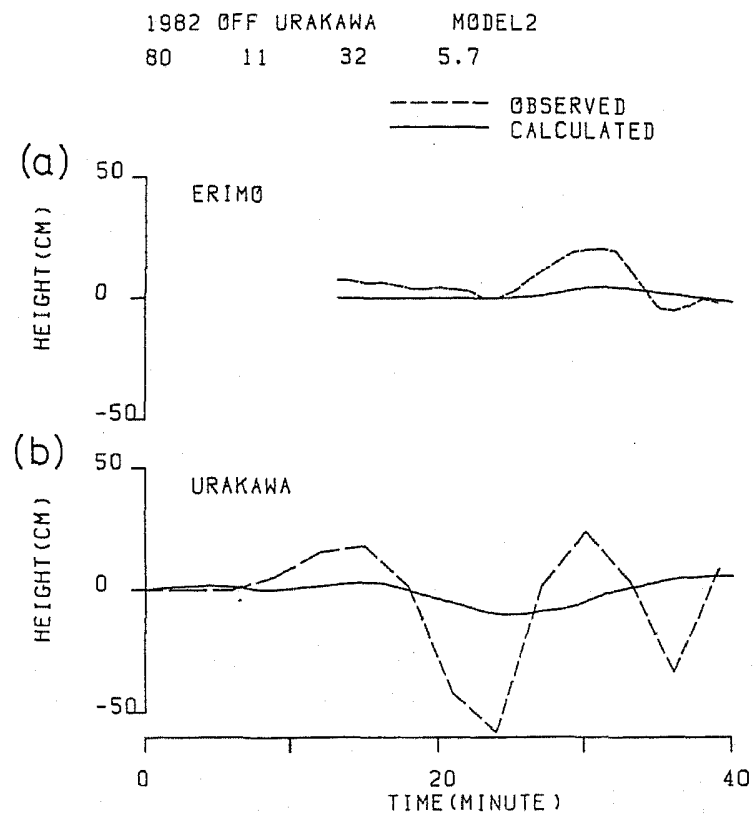

Fig. 10. Same as Fig. 9 but for the fault model 2. 


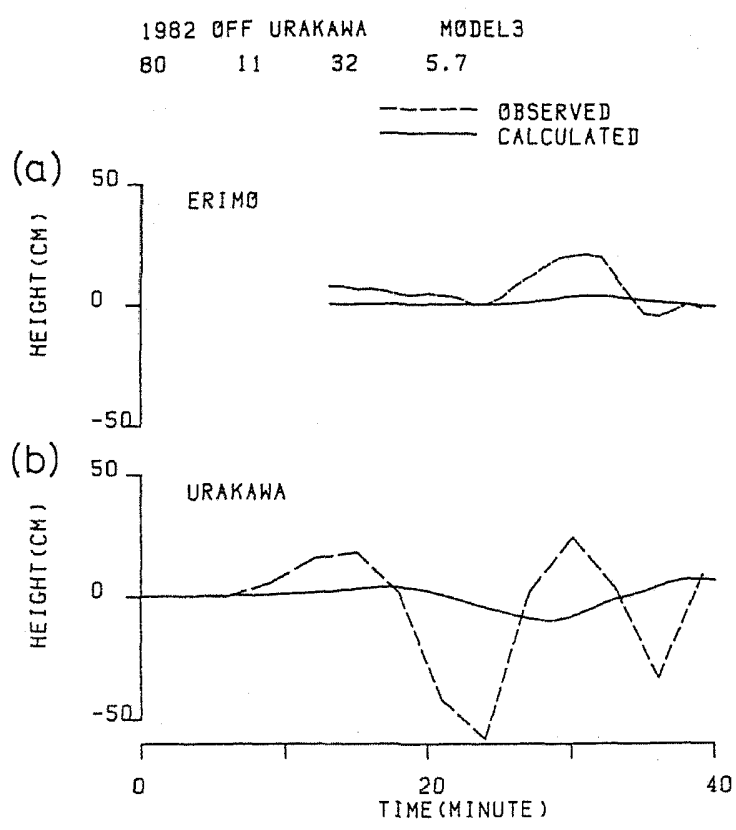

Fig. 11. Same as Fig. 9 but for the fault model 3.

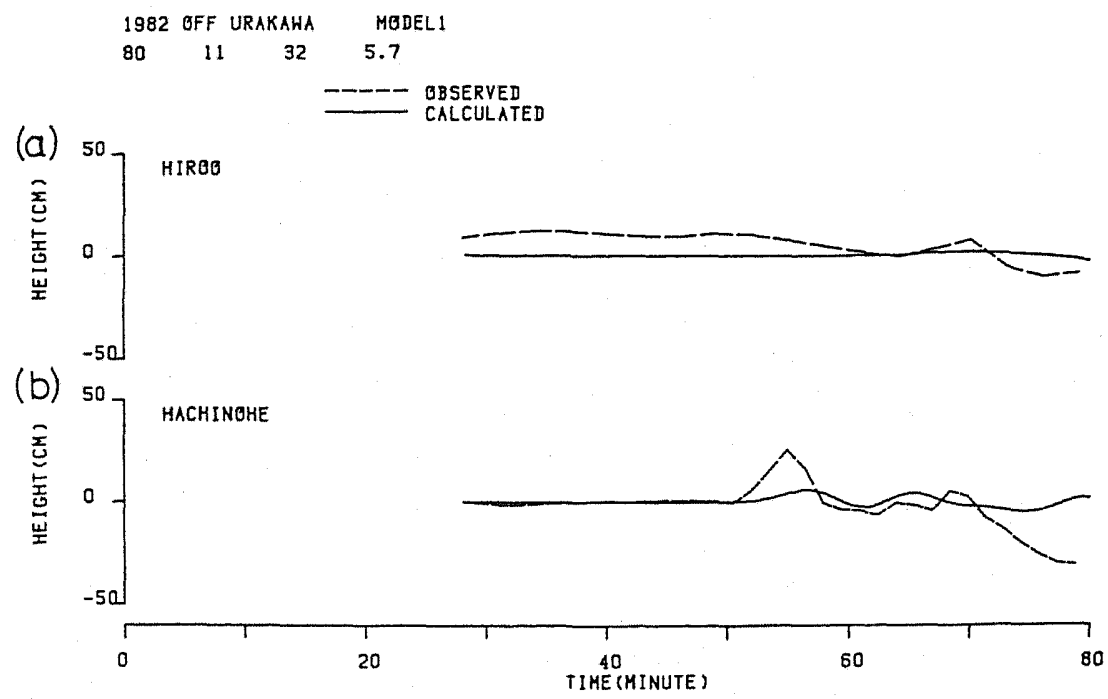

Fig. 12. Same as Fig. 9 but for Hiroo and Hachinohe. (a) Hiroo. (b) Hachinohe.

seismic waves, the crustal deformation around the focal area, and the tsunami data. Figure 13 illustrates the location and the geometry of model 1 . The fault is dipping toward the northeast and in agreement with TADA's (1987) model. 
(a)

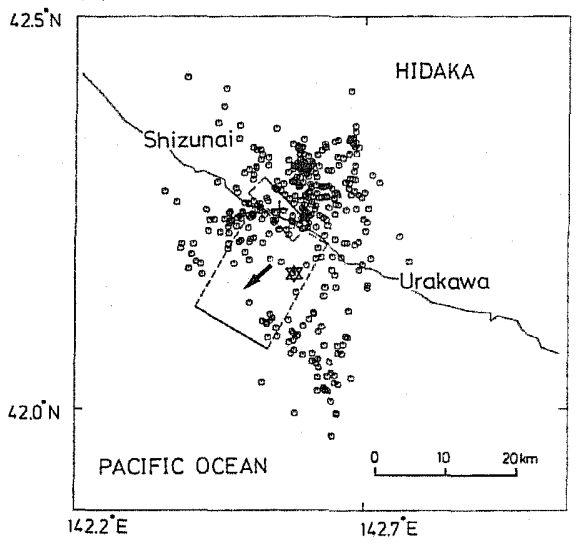

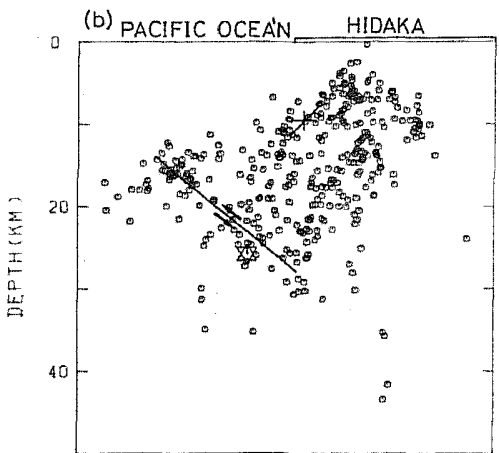

Fig. 13. Locations and geometries of fault models for the Urakawa-Oki earthquake (fault model 1) and its largest aftershock. The aftershock distribution is also plotted. Arrows indicate the direction of the slip vector. Other symbol conventions are the same as in Figs. 5 and 6. (a) Projection of the fault models onto the ground surface. (b) Projection of the fault models onto the vertical plane striking $\mathrm{N} 30^{\circ} \mathrm{E}-\mathrm{S} 30^{\circ} \mathrm{W}$ direction.

Since KaIZUKA (1972), many geologists and geophysicists have proposed the hypothesis that the Kuril arc is shifting westward and colliding with the Tohoku arc (e.g., Den and HotTA, 1973; Kimura et al., 1983; MoriYa, 1986). They state that the Hidaka Mountains have been created by overthrusting of the crust of Eastern Hokkaido upon that of Western Hokkaido. The horizontal displacement survey between 1915-1982 in Hokkaido reveals the westward movement of the easternmost Hokkaido (TADA and KIMURA, 1985). This observation is consistent with the hypothesis. The collision must generate a stress field of the NE-SW compression in central Hokkaido. The pressure axes of the Urakawa-Oki earthquake and its largest aftershock (Fig. 3) are close to that expected from the collision. MoriYa et al. (1983) have shown that other shallow earthquakes in the Hidaka region also have pressure axes of E-W or NE-SW directions. The generation of the Urakawa-Oki earthquake may be attributed to the overthrusting of the Kuril arc upon the Tohoku arc.

We wish to thank Takashi Tada for sending the leveling data to us. For the tsunami simulation we used the tide gauge records digitized by Susumu Takahashi and the computer program written by Sigeru Yamaki. Hiroki Miyamachi and Takeo Moriya kindly gave us their pre-publication results on the aftershock distribution. We are indebted to the members of Research Center for Earthquake Prediction, Hokkaido University, for permission to use their data. The IDA data used in this study were made available by courtesy of the IDA project team at the Institute of Geophysics and Planetary Physics, University of California, San Diego. The computations were made on HITAC M280H and $\mathrm{M} 680 \mathrm{H}$ at the Computer Center, Hokkaido University. 


\section{REFERENCES}

ABE, K., Reliable estimation of the seismic moment of large earthquakes, J. Phys. Earth, 23, 381-390, 1975.

ABE, K., Magnitude of the tsunami following the Urakawa-Oki, Japan, earthquake of March 21, 1982, in General Report on the Urakawa-Oki, Japan, Earthquake, of March 21, 1982, pp. 71-76, 1983 (in Japanese with English abstract).

Agnew, D., J. BERGER, R. Buland, W. FARRELL, and F. GILBERT, International Deployment of Accelerometers: A network for very long period seismology, EOS, 57, 180-188, 1976.

AIDA, 1., Numerical experiments for the tsunami propagation-the 1964 Niigata tsunami and the 1968 Tokachi-oki tsunami, Bull. Earthq. Res. Inst., Univ. Tokyo, 47, 673-700, 1969.

AIDA, I., Reliability of a tsunami source model derived from fault parameters, J. Phys. Earth, 26, 57-73, 1978.

AKI, K. and P. G. Richards, Quantitative Seismology, Vol. 1, W. H. Freeman, San Francisco, $557 \mathrm{pp}, 1980$.

DEN, N. and H. HotTA, Seismic refraction and reflection evidence supporting plate tectonics in Hokkaido, Pap. Meteorol. Geophys., 24, 31-54, 1973.

Dziewonski, A. M. and D. L. ANDerson, Preliminary reference Earth model, Phys. Earth Planet. Inter., 25, 297-356, 1981.

Dziewonski, A. M., A. Friedman, D. Giardini, and J. H. Woodhouse, Global seismicity of 1982: Centroid-moment tensor solutions for 308 earthquakes, Phys. Earth Planet. Inter., 33, 76-90, 1983.

FITCH, T. J., D. W. MCCowaN, and M. W. ShiELds, Estimation of the seismic moment tensor from teleseismic body wave data with applications to intraplate and mantle earthquakes, J. Geophys. Res., 85, 3817-3828, 1980.

Geller, R. J., Scaling relations for earthquake source parameters and magnitudes, Bull. Seismol. Soc. Am., 66, 1501-1523, 1976.

GEOGRAPHICAL SURVEY INSTITUTE, Vertical movement associated with 1982 off Urakawa earthquake in the southern part of Hokkaido, Rep. Coord. Comm. Earthq. Predict., 28, 21-23, 1982 (in Japanese).

HATORI, T., An investigation of tsunami generated by the Urakawa-Oki earthquake of 1982, Bull. Earthq. Inst., Univ. Tokyo, 57, 525-535, 1982 (in Japanese with English abstract).

KAIZUKA, S., Macro-topography of the island arc system and plate tectonics, Kagaku, 42, 573-581, 1972 (in Japanese).

KANAMORI, H. and J. W. Given, Use of long-period surface waves for rapid determination of earthquake-source parameters, Phys. Earth Planet. Inter., 27, 8-31, 1981.

Kimura, G., S. MiYashita, and S. MiYasaKa, Collision tectonics in Hokkaido and Sakhalin, in Accretion tectonics in the Circum-Pacific Regions, ed. M. Hashimoto and S. Uyeda, pp. 123-134, TERRAPUB, Tokyo, 1983.

Lawson, C. L. and R. J. Hanson, Solving Least Squares Problems, Prentice-Hall, Englewood Cliffs, N. J., 340 pp., 1974.

Mansinha, L. and D. E. SMYLIE, The displacement fields of inclined faults, Bull. Seismol. Soc. Am., 61, 1433-1440, 1971.

MiYamaCHI, H. and T. MoRIYA, Velocity structure and aftershock distribution of the 1982 Urakawa-Oki earthquake, J. Phys. Earth, 35, 309-326, 1987. 
MORIYA, T., Collision of forearcs and overlapped deep seismic zone in the transitional zone between the Northern Honshu and Kurile arcs, J. Phys. Earth, 34, Suppl., S175-S192, 1986.

Moriya, T., H. MryamaChI, and S. KaTOH, Spatial distribution and mechanism solutions for foreshocks, mainshock and aftershocks of the Urakawa-Oki earthquake of March 21, 1982, Geophys. Bull. Hokkaido Univ., 42, 191-213, 1983 (in Japanese with English abstract).

Strelitz, R. A., Moment tensor inversions and source models, Geophys. J. R. Astron. Soc., 52, 359-364, 1978.

TADA, T., Fault model of the 1982 Urakawa-Oki earthquake and its tectonic significance, Progr. Abstr. Seismol. Soc. Jpn., 1982(2), 3 (in Japanese).

TADA, T., Fault model of the 1982 Urakawa-Oki earthquake and its tectonic significance, Zisin, Ser. 2, 40, 27-37, 1987 (in Japanese with English abstract).

TADA, T. and G. Kimura, Collision of the outer Kurile arc and crustal deformation in the eastern Hokkaido, Progr. Abstr. Seismol. Soc. Jpn., 1985(1), 62 (in Japanese).

TAKAHASHI, S. and I. YAKUWA, The tsunami accompanied with the Urakawa-Oki earthquake of March 21, 1982, in General Report on the Urakawa-Oki, Japan, Earthquake, of March 21, 1982, pp. 77-85, 1983 (in Japanese with English abstract).

TAKEO, M., M. KASAHARA, and K. ABE, Focal process of the Urakawa-Oki earthquake of March 21, 1982, in General Report on the Urakawa-Oki, Japan, Earthquake, of March 21, 1982, pp. 1-11, 1983 (in Japanese with English abstract).

TaKeuchi, H. and M. SaIto, Seismic surface waves, in Methods in Computational Physics, Vol. 11, pp. 217-295, Academic Press, New York, 1972.

TANIMOTO, $\mathrm{T}$. and $\mathrm{H}$. KANAMORI, Linear programming approach to moment tensor inversion of earthquake sources and some tests on the three-dimensional structure of the upper mantle, Geophys. J. R. Astron. Soc., 84, 413-430, 1986. 